\title{
Paracellular barrier and channel functions of TJ claudins in organizing biological systems: Advances in the field of barriology revealed in knockout mice
}

\author{
Atsushi Tamura and *Sachiko Tsukita \\ Laboratory of Biological Science, Graduate School of Frontier Biosciences and Graduate School \\ of Medicine, Osaka University, Osaka, Japan. \\ ${ }^{*}$ Corresponding author
}

\begin{abstract}
Claudin was first identified as a four-transmembrane protein in the tight junctions (TJs) between epithelial cells. The claudin family has 27 members, which are specifically expressed depending on the epithelial cell type. Accumulating evidence has revealed that claudins are responsible for the paracellular barrier that prevents molecules from passing through epithelial cell sheets. In addition, the extracellular domains of some claudins enable them to act as a permselective paracellular channel for specific molecules, including ions and non-ionic solutes. Recent studies using claudin knockout mice revealed that the loss of claudins' specific paracellular barrier and/or channel functions affects particular biological functions and leads to pathological states. In this review, considering recent findings in vivo, we describe how, sometimes in concert with canonical transporters and channels, the paracellular barrier and channel functions of claudins sophisticatedly organize biological systems.
\end{abstract}




\section{Introduction:}

The role of epithelial barriers caused by tight junctions $\left(T J_{S}\right)$ in regulating homeostasis in the compartments of the body: The field of barriology

A multicellular organism enclosed by an epithelial cell sheet is separated into inner and outer parts[1]. The internal part of the body is further divided into many other compartments by sheets of epithelial cells (including endothelial and mesothelial cells), such as body cavities, intestinal lumens, blood vessels, nasal cavities, seminiferous tubules, thyroid gland follicles, and oviducts. Specific small and large compartments exist throughout the body; an organ is essentially a combination of epithelial cell sheet-lined compartments. The mechanism that prevents solutes from leaking between cells in the partition that separates the compartments is called the "paracellular barrier" [2-4]. On the other hand, the epithelial cell body itself serves as a barrier, the "transcellular barrier," due to its plasma membrane. The homeostasis in each epithelial cell sheet-lined compartment is not static, but is dynamically maintained by the paracellular and transcellular barrier and the selective exchange of molecules across the epithelial cell sheet barrier.

\section{Identification of claudins as the basic epithelial TJ proteins}

Although the concept of tight junction(TJ)-based paracellular barrier has been developed after 1885 primarily from the morphological and physiological aspects, the contribution of cell-cell adhesive membrane proteins to TJ formation was not established, until the TJ claudins were identified to play this role, in 1998, when it leads to the field of Barriology [5-11].

Although the identity of the unique TJ transmembrane molecules was an intriguing mystery for many years, mainly because the $\mathrm{TJ}$ is a very insoluble structure that is not easily accessed by conventional cell biological methods. Thus, the identification of TJ proteins required a novel procedure for 
isolating cell-cell junctions[12], as previously described [13]. Since the first TJ essential transmembrane proteins, claudin-1 and -2 , were identified as four-transmembrane domain proteins in 1998, a total of 27 claudin family members have been reported in mouse and human [6,7,14]. In addition to the four transmembrane domains, claudins have a long, first extracellular loop that includes a claudin-motif W-GLW-C-C, and a shorter second extracellular loop. The amino acid identity between claudin family members is not high, generally about $30 \%[15,16]$. Thus, claudins are multi-gene family proteins with different properties, that are expressed in different parts of the body, where they perform various functions $[9,10,17,18]$.

Most claudin family members are mainly expressed in epithelial cells, although a few of them are expressed in non-epithelial cells; for example, claudin-11 and -19 are expressed in oligodendrocytes and Schwann cells. Claudin-6 is expressed in pluripotent stem cells, and claudin-8 in undifferentiated spermatogonia [19-22], to have other functions than those as adhesion molecules, for example, as a TJ platform for cell signaling. Such functions have been observed in some cancer cells that originated from epithelial cells $[23,24]$. The expressions of claudins are regulated by many factors, including epithelial-mesenchymal transition (EMT)-related transcription factors, hormone- and various cytokines, and others $[17,25,26]$. In general, most claudins are epithelial TJ proteins that are down-regulated by EMT factors.

\section{Organ-dependent expressions of claudin family members}

Organs include many types of epithelial cells, in which claudins exhibit distinct expression patterns. In most epithelia, more than three species of claudins are expressed, which vary in type and relative amount. At one extreme, only a few (1-3) claudin species are very dominantly expressed in a tissue and at the other, nearly all the claudins are expressed and produce an averaged effect. There are also various intermediate cases that lie between these two extreme ones [16,18]. 
For example, claudin-11 and claudin-18 (stomach type) is very dominantly expressed in the sertoli cells in testis and the stomach, respectively [19,27]. In the liver, claudins $-1,2$, and 3 are dominant, whereas many claudin species are expressed in the kidney [28]. There are also location-dependent differences in the distribution of claudins within an organ. Thus, the expressed claudins are different between organs, between tissues, and between epithelial cells. It is likely that the multiplicity of claudin expression patterns is important for their variety of functions in organs.

\section{Characterization of claudins as paracellular barrier proteins, and as paracellular channel proteins in some cases}

As described above, claudins were first characterized as TJ proteins because of their TJ localization [6,7]. Although other membrane proteins, like occludin, tricellulin, JAM, and CAR have also been identified as TJ proteins, claudins are the most essential, because they form the TJ strands that create the paracellular barrier [8,29-31]. Claudin is the only protein which can form steady strands in overexpressed fibroblasts which originally don't express claudin molecules.

When exogenously expressed, claudins were integrated into pre-existing TJs, the claudins appeared to contribute mostly to the TJs' paracellular barrier function, because morphologically, the gaps between cells were very narrow at the TJs, almost zero, which would inhibit the free permeation of molecules at least of large size [2]. When the ion transport was physiologically estimated across epithelial cell sheets in which claudins were exogenously expressed, many claudin subtypes decreased the ion permeation, as expected for paracellular barrier proteins. On the other hand, the ion permeation was increased by some claudins, indicating that they acted as paracellular ion channels. This role is exemplified by claudins $-2,-10 \mathrm{~b}$, and -15 for cations and claudins $-4,-7$, and -10 a for anions[18].

Based on the few epithelial physiological studies examining non-ionic 
solute-permeation, it is speculated that certain claudin species allow non-ionic solute permeation in a size-dependent manner at least for the small molecules. The regulation of water transport by claudins was recently studied $[32,33]$. However, it is premature to discuss this point, because another possible mechanism, in which solute permeation is determined by the rearrangement or dynamism of TJ strands, has also been proposed. The mechanism and pattern analyses of the proposed mechanisms, as well as that of channel function of claudins, remain to be challenged.

Regarding the TJ channel pore size, accumulated studies have indicated that TJ channels have a radius of about 4 - $6 \AA$. For example, a radius of 5.2 $\AA$ was reported for the TJ channels in the human colon cancer cell line $\mathrm{CaCO} 2$ [34]. A radius of $4.3 \AA$ and $4.5 \AA$ was reported in $\mathrm{T} 8$ and $\mathrm{CaCO} 2$ cells [35,36], respectively, and another study using PEG analysis suggested that the radius is $\sim 4 \AA$ [37]. In addition, channels with a larger radius, of $8 \AA$ and $6.5 \AA$, were reported in certain parts of the body [37]. Although the channel size has not been systematically studied with respect to specific claudin species, it was recently shown that claudin-2 forms a pore with a $3.25-\AA$ radius [38].

In summary, claudins are the TJ proteins that form the paracellular barrier in epithelial cell sheets. Some claudins also appear to form TJ paracellular channels in cell sheets to allow the selective permeation of ions, including cations and anions, and of solutes in a size-dependent manner. The mechanisms underlying these restricted permeabilities will be revealed by expanded structure-function studies of specific claudins.

\section{Structure of TJ claudin}

One of the most powerful approaches to studying the paracellular barrier and channel is the high-resolution crystallography of transmembrane proteins [39]. Recently, the crystal structure of claudin-15 was clarified to 2.4- $\AA$ resolution, which revealed a characteristic $B$-sheet fold comprised of two extracellular segments and five B-strands connected to a four-helix 
transmembrane motif [40]. The five B-sheets extend on the outer surface of the membrane, forming a palm-like configuration. The structural analysis further showed that W-GLW and CC of the W-GLW-CC in the claudin motif contributes to the stability of the extracellular loop. The hydrophobic portion around M68 in the extracellular helix $(\mathrm{ECH})$ domain of the first extracellular loop fits into a hydrophobic pocket around F146, F147, and L158 of a neighboring claudin molecule, thus forming the cis-interaction of claudins in the same cell.

In addition, in claudin-15, the 5-6-sheet extracellular domain creates a negatively charged palm-figured platform, which presumably provides the basis for the paracellular channel selectivity for cations. Thus, the characteristic high-resolution structure of this claudin revealed the basis for the molecular interactions that create the TJ paracellular barrier and channel.

\section{TJ claudins as organizers of paracellular and intracellular events}

The TJs also play important roles in intracellular events, such as those related to cytoskeletal networks, signaling pathways, and vesicle trafficking. In these processes, claudins are directly associated with scaffold proteins,

such as ZO1/2 [8,41]. Hence, TJs play crucial roles in paracellular and intracellular functions, and in their cooperative functions. However, we are focusing on the paracellular role of TJs in organizing biological systems in this review.

\section{Paracellular roles of claudins in biological systems as revealed by knockout (KO) mouse studies}

The paracellular barrier function of TJ claudins is probably the simplest to interpret experimentally, since their dysfunction leads to the diffusion of some molecules that are normally blocked, although the specificity of the 
barrier function for various kinds of molecules differs between claudins. The roles of specific claudins in organizing biological systems that respond to environmental cues, have begun to be revealed by in vivo analyses of $\mathrm{KO}$ mice. Compared to the paracellular barrier functions of claudins, their paracellular channel functions are much more sophisticated, since in many cases cooperation with other types of claudins and certain channels/ transporters is required to elicit the biological function. We note that, except in the case of a single-claudin TJ barrier that disappears upon the claudin's deficiency, the loss of a claudin usually does not disrupt the TJs, because other expressed claudins can form them. However, a property of the epithelium is usually altered to affect a specific biological function, thus suggesting a biological role for the targeted claudin.

\section{Specific paracellular barrier functions of claudins in biological systems suggested by knockout (KO) mouse studies}

Since claudins are the paracellular barrier proteins, the mechanism for barrier creation should be similar for all claudins; that is, they all closely attach to the two membranes of neighboring epithelial cells at their apical region. On the other hand, accumulating evidence indicates that different specific paracellular barrier functions occur under certain conditions, depending on the types of claudins involved. A paracellular barrier role has been suggested for claudins $-1,-3,-4,-5,-11,-18$, and -19 . KO mouse studies have been performed for claudins $-1,-4,-5,-11$, and -18 .

\subsection{Claudin-1 in the skin creates a water barrier}

Claudin-1, classified as a paracellular barrier-forming claudin, is expressed in various organs like liver, skin. In the skin, claudin-1 is predominantly expressed, along with other types of claudins, such as claudin-3 and -4 . In claudin-1-deficient mice in which the claudin was removed from TJs, water loss from the body was observed by measuring the transepidermal water loss 
(TEWL) after birth. These mice die of dehydration within a day after birth [42]. On the other hand, claudin-1 KO mice also show changes in the composition and barrier function of the stratum corneum (SC), suggesting a role for claudin-1 in skin-cell differentiation in addition to blocking water [43]. These findings pointed to the role of claudin-1 of skin epidermal sheets in organizing a waterproof cell sheet system on the entire surface of the body.

8.2. Claudin-4 prevents hydronephrosis in the kidney and may have roles in differentiation in the thymus, intestine, and urinary bladder

Although claudin-4 is generally considered to be a paracellular barrier type of claudin based on studies in cultured cells, there are some cases in which it forms a paracellular cation channel in combination with claudin-8 [44].

The kidney and urinary tract of KO mice of claudin-4 show hyperplasia and thickening of the urothelial layers, leading to lethal hydronephrosis due to urinary tract obstruction [45]. On the other hand, claudin-4 is a specific marker for Aire-expressing thymal epithelial cells and enteroendocrine cells in the intestine $[46,47]$. It is possible that claudin-4's role in differentiation is indirectly related to its paracellular barrier function.

\subsection{Claudin-5 in the brain forms the blood-brain barrier}

Claudin-5, which shows paracellular barrier activity when transferred into cultured cells, is expressed in endothelial cells, particularly in the brain [48,49]. Claudin-5 KO mice exhibit a lethal phenotype within 10 hours after birth, in which relatively small molecules $(<800 \mathrm{Da})$ but not larger ones, selectively leak into the brain through the dysregulated TJs of endothelial cells ([50] Nitta et al. 2003). This result clearly showed that claudin-5 plays a critical role in the blood-brain barrier (BBB). Such changes in the BBB provide a strategy for drug delivery through the BBB for the diseases like brain tumor or encephalitis. Furthermore, another report showed that the 
targeted suppression of claudin -5 decreased post-traumatic brain edema, an important finding that could lead to new therapies for the injured brain. Manipulation of the $\mathrm{BBB}$ is an important issue in drug delivery, for which claudin -5 is a promising target, due to its dominant role as a constitutive BBB paracellular barrier protein with size selectivity.

8. 4. Claudin-11 is important for saltatory conduction in the central nervous system and for spermatogenesis in the testis

Claudin-11, which was originally identified as oligodendrocyte-specific protein (OSP), is expressed in the TJs of oligodendrocytes in the central nervous system (CNS), and of sertoli cells in the testis, and of basal cells in the inner ear. The deletion of claudin-11 in mice causes slowed nerve conduction with hindlimb weakness, due to the loss of TJs in oligodendrocytes, which affects their physical shielding function [19]. In addition, these $\mathrm{KO}$ mice show defects in spermatogenesis due to the TJ barrier loss in sertoli cells [19]. Thus, although clear mechanisms remain unknown, claudin-11 KO mice show both slowed nerve conductance and male sterility due to TJ paracellular barrier loss.

\section{5. Claudin-11 and claudin-14 in the inner ear prevent deafness}

In the inner ear, the endolymph potential (EP) is affected by a deficiency of claudin-11 in basal cells that results in TJ loss [51,52]. Consequently, a defect in the EP was caused without $\mathrm{K}+$ concentration changes in the cochlear duct, resulting in deafness. In KO mice lacking claudin-14, which is expressed in the outer hair cells (OHCs), a high $\mathrm{K}^{+}$concentration around the basolateral side of the epithelial OHCs causes prolonged OHC depolarization that leads to cell death. Both Claudin-11 KO and claudin-14 KO cause deafness, but the deafness results from deficiencies in different parts of the inner ear. Thus, for hearing, the TJs of several kinds of cochlear duct-surrounding epithelial cells are required to maintain the EP in the inner ear. 


\subsection{Claudin-18 controls inflammation in the stomach and lung}

Claudin-18 has two major alternative splicing forms, which are dominantly expressed in the stomach (claudin-18 stomach type: claudin-18-2), and in the lung (claudin-18 lung type: claudin-18-1)[53].

The stomach of claudin-18 KO mice shows the paracellular leakage of $\mathrm{H}^{+}$ ions, which causes prolonged acute inflammation as gastritis [27] whereas the molecular mechanism in detail was not clarified. In the lungs of the claudin-18 KO mice, solute permeability and alveolar fluid clearance are increased [54]. Thus, the claudin-18-based paracellular barrier plays a role in controlling inflammation in both the stomach and lungs.

\subsection{Claudin-19 in peripheral nerves is involved in saltatory nerve} conduction

Claudin-19 is expressed in the kidney and lung. It is also expressed in the TJs of peripheral nerves, and in TJ-like structures in Schwann cells that are detected by electron microscopy.

The general morphology of claudin-19-deficient Schwann cells appears normal, at both the internodal regions and the nodes of Ranvier, except that the TJs are completely missing from the outer and inner mesaxons. This tissue composition is thought to be important for the saltatory conduction in neural transmission, by blocking the leakage of ions between the neural axon and Schwann cells. In KO mice of claudin-19, this saltatory conductance is delayed, suggesting that claudin-19 acts in the non-epithelial Schwann cells, to electrically seal the compartment between the neural axon and Schwann cells, which is critical for saltatory conduction in the peripheral nervous system[20].

9. Specific paracellular channel functions of claudins in biological systems suggested by knockout (KO) mouse studies 
A paracellular channel role has been suggested for claudins $-2,-7,-10,-15$, -16 , and in limited cases for claudin-4. KO mouse studies supporting this role have been performed for claudins $-2,-10,-15$, and -16 .

\subsection{Claudin-2 in the kidney acts as a paracellular Na+channel for} Nat-reabsorption in proximal convolute tubules

Claudin-2 was the first channel-forming claudin to be described [29]. Claudin-2 increases the conductance of TJs when it is exogenously expressed in cultured MDCK epithelial cells; specifically, it increases the paracellular permeability for inorganic and organic cations [55]. It was recently suggested that claudin-2 also increases the permeability for water [32]. Mice in which claudin-2 is systemically lost by gene knockout are fertile, grow normally, and have a normal appearance $[33,56]$. However, their kidneys show a $\mathrm{Na}+$ reabsorption defect due to loss of the claudin-2-based $\mathrm{Na}+$ channel function in renal proximal tubules.

\subsection{Claudin-2 in the liver plays a role in the hepatobiliary system}

Claudin-2 is specifically expressed in the perivenous regions of the hepatic lobule in the liver. In contrast, claudin-1 and -3 are expressed in both the perivenous and periportal zones.

In claudin-2 KO mice, the concentrations of bile acids, phospholipids, and cholesterol are significantly increased in the bile, although the ion concentrations are not greatly changed [28]. The bile flow rate in the claudin-2 $\mathrm{KO}$ mice is about half that of wild-type mice, suggesting that the paracellular ion and water permeation are decreased as a result of claudin-2 paracellular channel loss. In this respect, the ion and water permeabilities were shown to decrease in these mice, in experiments using isolated intrahepatic bile ducts and primary cultured hepatocytes. Under a lithogenic diet, the claudin-2-deficient mice develop gallstones. 
These observations revealed the existence of a claudin-2-based hepatobiliary system, which is particularly important for the composition and flow of bile in the bile canaliculi. Although these changes of bile leads to gallstones, it is more remarkable that the paracellular channel role of claudin-2 provides the motive force for the flow from the blind terminal of the bile canalicular counter-current system, through the paracellular flow of cations and water from the sinusoidal vessels in the hepatobiliary system.

\subsection{Claudin-2 and claudin-15 in the intestine play a role in coupling nutrient} absorption to nutrient transporters

Claudin expression is spatiotemporally regulated in the intestine [57-59]. Claudin-3 and -7 are expressed in epithelial cells in both crypts and villi throughout the intestine, and claudin-4 is expressed in villi tip epithelial cells and enteroendocrine cells. Notably, the pattern of claudin-2 expression in the intestine changes with age. In infant mice before weaning, claudin-2 is expressed in the crypts and villi, while in adult mice it is expressed only in the crypts. The expression of claudin-15 shows the complementary pattern: in infants only in crypts, and in adults in crypts and villi. Since claudin-2 and -15 are the TJ claudin channels in the intestine, their deficiencies were systematically examined in single and double knockout (DKO) mice $[56,59,60]$. The Na+-permeability across the intestinal epithelia was decreased compared to that of wild-type mice, slightly and greatly in the claudin-2 and claudin-15 single KO mice, respectively in adult stage [56]. The effect was severe in the DKO case [60]. Hence, the Na+ concentration in the intestinal lumen decreased according to the reduction in $\mathrm{Na}+$ permeability, resulting in lethality in the DKO mice. This is because in the DKO mice, the nutrition absorption was almost completely blocked due to the inactivation of nutrient transporters, which depend on $\mathrm{Na}+$ concentration gradient from intestinal lumen to cytoplasm of intestinal epithelial cells. The single-KO mice of claudin-15 and - 2 showed moderate and mild tendencies toward these effects, respectively. 
The results of the DKO mouse study revealed that there exists a sophisticated biological system for controlling the paracellular flow of $\mathrm{Na}+$ from the serosal to the mucosal sides of the intestinal wall, through paracellular TJ channels of claudin-2 and -15 across epithelial cell sheets. This system is coupled with the activity of Na+-dependent nutrient transporters, to allow nutrient absorption from the intestinal lumen across the intestinal epithelial cells, pointing to that the cooperation of paracellular and transcellular transport systems is involved in the organization of the biological systems in the body, a novel framework of biological system.

\subsection{Claudin-7 in kidney for urinary $\mathrm{Na}+\mathrm{Cl}$-, and $\mathrm{K}+$ wasting and in} intestine for control of inflammation

Claudin-7 is expressed in various organs like intestine, lung and kidney. While claudin-7 overexpression induce $\mathrm{Cl}^{-}$permeability decrease and $\mathrm{Na}+$ permeability increase in LLC-PK1 cells, claudin-7 knockdown induce $\mathrm{Na}+$ permeability in MDCK cell and decrease Cl- permeability in LLC-PK cells [31,61]. The some inconsistency between these results might be suggested by various expression level of claudin-17, anion channel type claudin.

In claudin-7 $\mathrm{KO}$ mice, urinary $\mathrm{Na}+, \mathrm{K}+$ and $\mathrm{Cl}-$ waste, dehydration was observed due to the decrease in the paracellular $\mathrm{Cl}^{-}$permeability. This mouse in intestine shows severe intestinal inflammation and lethal phenotype within pnd 12 . In this mouse, integrin-2 expression and normally formed claudin-7/integrin-2/claudin-1 complex was disrupted, which induce up-regulation of matrix metalloproteinases (MMPs) inducing intestinal epithelial tissue damage and inflammation [62,63].

9.5. Claudin-10 loss in the kidneys causes hypermagnesemia and nephrocarcinosis

Although claudin-10 has several alternative splicing forms, its major expression patterns are classified into two splicing forms, claudin-10a and 
$-10 \mathrm{~b}$ [64]. Whereas claudin-10b is expressed in various organs, claudin-10a is expressed mainly in the kidney, especially in the thick ascending limb (TAL) of Henle's loop. Although claudin-10a and -10b use the same exons except for the first coding exon, which contributes to the first transmembrane region and first half of the extracellular regions, they show different paracellular permselectivities: claudin-10b acts as a cation-selective channel, and claudin-10a as an anion-selective one.

In claudin-10 KO mice in which both of the splicing forms are deleted specifically in the TAL, hypermagnesemia and nephrocarcinosis are observed due to a decrease in the paracellular $\mathrm{Na}+$ permeability and an increase in the paracellular $\mathrm{Mg} 2+$ and $\mathrm{Ca} 2+$ permeability [65].

\subsection{Claudin-16 in the kidney promotes $\mathrm{Mg} 2+$ and Ca2+ reabsorption by} generating a lumen-positive transepithelial potential in the TAL

Claudin-16 is also called paracellin. The analysis of human paracellin, which provided the first description of an in vivo function of claudins, was followed by analyses in gene-targeted mice. In patients with mutations in paracellin genes, Mg2 + reabsorption in the TAL is disturbed, leading to hypomagnesemia.

In claudin-16 knockdown mice[66], the $\mathrm{Mg} 2+$ and $\mathrm{Ca} 2+$ reabsorption is decreased due to the reduced lumen-positive transepithelial potential and decreased paracellular $\mathrm{NaCl}$ dilution potential. Although claudin-16 was suggested to be a $\mathrm{Mg} 2+$ and $\mathrm{Ca} 2+$ channel in early studies, its $\mathrm{Na}+$ channel activity was clearly revealed in this mouse study. An interaction between claudin-16 and claudin-19 in the TAL is probably critical for the high TJ cation selectivity, which generates enough lumen-positive transepithelial potential for $\mathrm{Mg} 2+$ and $\mathrm{Ca} 2+$ reabsorption.

In contrast, in claudin-16 KO mice, the paracellular $\mathrm{Na}+$ permeability was not changed in the KO mice, suggesting that claudin-16 alone performs the divalent cation channel role in the TAL [67]. In any case, there appear to be at least two molecular systems for claudin-16's role. 


\section{Conclusion and Perspectives}

The TJ paracellular barrier proteins are claudins, of which there are 27 family members. Some claudin family members form paracellular channels for select molecules, such as ions and non-ionic solutes. The paracellular barrier and channel functions of claudins are critical microenvironmental regulators in the body, and their roles should be systematically analyzed as "barriology" [7,9]. The claudins determine the functional parameters of epithelial cell sheets, which not only enclose the large and small compartments of the body but also define the compartments' specific homeostasis. Thus, the claudins in epithelial cells help to organize biological systems, many of which have been revealed by KO mouse studies.

The functional analyses of claudins combined with their structural biological analyses will lead to new therapeutic strategies for various diseases as well as preventative approaches for maintaining and promoting good health. In this respect, the control of inflammation by claudin 7 or 18 is particularly important for preventing various cancer states. The regulation of claudin- 5 should lead to methods for controlling the BBB to ease drug delivery to the brain. The regulation of nutrition absorption by claudins 2 and 15 revealed a new basic physiological system, which will be applicable to maintaining good health, including appropriate body weight. The regulation of bile flow and the associated hepatobiliary system by claudin- 2 and the kidney ion reabsorption system by claudin-16 also have important implications for health. Considering that functional analyses using gene KO strategies are beginning to reveal new physiological functional schemes, further studies will reveal higher-ordered biological systems and new methods for manipulating biological systems in highly sophisticated ways to lead to a novel scheme for preventive medicine and for medical therapy.

\section{Acknowledgments}


We thank all the members of our laboratory for helpful discussions. We thank Drs. H.Suziki, K.Tani, and Y.Fujiyori in Nagoya University for collaboration and discussion. Our program is supported by Grants-in-Aid for Scientific Research (A) and Creative Scientific Research from the Ministry of Education, Culture, and Sports, Science and Technology of Japan, and by CREST (Core Research for Evolutional Science and Technology) of Japan Science and Technology Agency to Sachiko Tsukita. 


\section{References}

[1]Frömter E, Diamond J. Route of passive ion permeation in epithelia. Nat New Biol. 1972:235:9-13. No abstract available.

[2] Farquhar MG, Palade GE. Junctional complexes in various epithelia. J Cell Biol. 1963;17:375-412.

[3] Claude P, Goodenough DA. Fracture faces of zonulae occludentes from "tight" and "leaky" epithelia. J Cell Biol. 1973;58:390-400.

[4] Powell DW. Barrier function of epithelia. Am J Physiol. 1981;241:G275-88.

[5]Ehrlich P. Das Sauerstoff-Bedurfnis des Organismus: Eince farbenanalytische Studie. Hirschwald, Berlin 1885;8:167.

[6] Furuse M, Fujita K, Hiiragi T, Fujimoto K, Tsukita S. Claudin-1 and -2: novel integral membrane proteins localizing at tight junctions with no sequence similarity to occludin. J Cell Biol. 1998;141:1539-50.

[7] Tsukita S, Furuse M, Itoh M. Multifunctional strands in tight junctions. Nat Rev Mol Cell Biol. 2001;2:285-93.

[8] Umeda K, Ikenouchi J, Katahira-Tayama S, Furuse K, Sasaki H, Nakayama M, Matsui T, Tsukita S, Furuse M, Tsukita S. Z01 and Z0-2 independently determine where claudins are polymerized in tight-junction strand formation. Cell 2006;126:741-54.

[9] Tsukita S, Yamazaki Y, Katsuno T, Tamura A, Tsukita S. Tight junction-based epithelial microenvironment and cell proliferation. Oncogene 2008; 27:6930-6938.

[10] Anderson JM, Van Itallie CM. Physiology and function of the tight junction. Cold Spring Harb Perspect Biol. 2009;1:a002584.

[11] Furuse.M. Molecular basis of the core structure of tight junctions. Cold Spring Harb Perspect Biol. 2010;2:a002907.

[12] Tsukita S, Tsukita S. Isolation of cell-to-cell adherens junctions from rat liver. J Cell Biol. 1989;108:31-41.

[13] Franke WW. Discovering the molecular components of intercellular junctions--a historical view. Cold Spring Harb Perspect Biol. 2009;1:a003061.

[14] Mineta K, Yamamoto Y, Yamazaki Y, Tanaka H, Tada Y, Saito K, Tamura A, Igarashi M, Endo T, Takeuchi K, Tsukita S. Predicted expansion of the claudin multigene family. FEBS Lett. 2011 ;585:606-12.

[15] Morita K, Furuse M, Fujimoto K, Tsukita S. Claudin multigene family 
encoding four-transmembrane domain protein components of tight junction strands. Proc Natl Acad Sci U S A. 1999 19;96:511-6.

[16] Mitic LL, Van Itallie CM, Anderson JM. Molecular physiology and pathophysiology of tight junctions I. Tight junction structure and function: lessons from mutant animals and proteins. Am J Physiol Gastrointest Liver Physiol. 2000;279:G250-4.

[17] Turner JR. Intestinal mucosal barrier function in health and disease. Nat Rev Immunol. 2009;9:799-809.

[18] Günzel D, Yu AS. Claudins and the modulation of tight junction permeability. Physiol Rev. 2013;93:525-69.

[19] Gow A, Southwood CM, Li JS, Pariali M, Riordan GP, Brodie SE, Danias J, Bronstein JM, Kachar B, Lazzarini RA. CNS myelin and sertoli cell tight junction strands are absent in Osp/claudin-11 null mice. Cell. 1999;99:649-59.

[20] Miyamoto T, Morita K, Takemoto D, Takeuchi K, Kitano Y, Miyakawa T, Nakayama K, Okamura Y, Sasaki H, Miyachi Y, Furuse M, Tsukita S. Tight junctions in Schwann cells of peripheral myelinated axons: a lesson from claudin-19-deficient mice. J Cell Biol. 2005;169:527-38.

[21] Wang L, Xue Y, Shen Y, Li W, Cheng Y, Yan X, Shi W, Wang J, Gong Z, Yang G, Guo C, Zhou Y, Wang X, Zhou Q, Zeng F. Claudin 6: a novel surface marker for characterizing mouse pluripotent stem cells. Cell Res. 2012;22:1082-5.

[22] McMillan M, Andronicos N, Davey R, Stockwell S, Hinch G, Schmoelzl S. Claudin-8 expression in Sertoli cells and putative spermatogonial stem cells in the bovine testis. Reprod Fertil Dev. 2014;26:633-44.

[23] Kwon MJ. Emerging roles of claudins in human cancer. Int $\mathrm{J}$ Mol Sci. 2013;14:18148-80.

[24] Ding L, Lu Z, Lu Q, Chen YH. The claudin family of proteins in human malignancy: a clinical perspective. Cancer Manag Res. 2013;5:367-75.

[25] Ikenouchi J, Matsuda M, Furuse M, Tsukita S. Regulation of tight junctions during the epithelium-mesenchyme transition: direct repression of the gene expression of claudins/occludin by Snail. J Cell Sci. 2003;116:1959-67.

[26] Capaldo CT, Nusrat A. Cytokine regulation of tight junctions. Biochim Biophys Acta. 2009 ;1788:864-71.

[27] Hayashi D, Tamura A, Tanaka H, Yamazaki Y, Watanabe S, Suzuki K, Suzuki 
K, Sentani K, Yasui W, Rakugi H, Isaka Y, Tsukita S. Deficiency of claudin-18 causes paracellular $\mathrm{H}+$ leakage, up-regulation of interleukin-18, and atrophic gastritis in mice. Gastroenterology. 2012;142:292-304.

[28] Matsumoto K, Imasato M, Yamazaki Y, Tanaka H, Watanabe M, Eguchi H, Nagano H, Hikita H, Tatsumi T, Takehara T, Tamura A, Tsukita S. Claudin 2 deficiency reduces bile flow and increases susceptibility to cholesterol gallstone disease in mice. Gastroenterology. in press

[29] Furuse M, Furuse K, Sasaki H, Tsukita S. Conversion of zonulae occludentes from tight to leaky strand type by introducing claudin-2 into Madin-Darby canine kidney I cells. J Cell Biol. 2001 16;153:263-72.

[30] Van Itallie CM, Fanning AS, Anderson JM. Reversal of charge selectivity in cation or anion-selective epithelial lines by expression of different claudins. Am J Physiol Renal Physiol. 2003;285:F1078-1084.

[31] Hou J, Gomes AS, Paul DL, Goodenough DA. Study of claudin function by RNA interference. J Biol Chem. 2006;281:36117-23.

[32] Rosenthal R, Milatz S, Krug SM, Oelrich B, Schulzke JD, Amasheh S, Günzel D, Fromm M. Claudin-2, a component of the tight junction, forms a paracellular water channel. J Cell Sci. 2010;123:1913-21. doi: 10.1242/jcs.060665.

[33] Muto S, Hata M, Taniguchi J, Tsuruoka S, Moriwaki K, Saitou M, Furuse K, Sasaki H, Fujimura A, Imai M, Kusano E, Tsukita S, Furuse M. Claudin-2-deficient mice are defective in the leaky and cation-selective paracellular permeability properties of renal proximal tubules. Proc Natl Acad Sci U S A. 2010;107:8011-6.

[34] Knipp GT, Ho NF, Barsuhn CL, Borchardt RT. Paracellular diffusion in Caco-2 cell monolayers: effect of perturbation on the transport of hydrophilic compounds that vary in charge and size. J Pharm Sci. 1997 ;86:1105-10.

[35] Watson CJ, Rowland M, Warhurst G. Functional modeling of tight junctions in intestinal cell monolayers using polyethylene glycol oligomers. Am J Physiol Cell Physiol. 2001;281:C388-97.

[36] Watson CJ, Hoare CJ, Garrod DR, Carlson GL, Warhurst G. Interferon-gamma selectively increases epithelial permeability to large molecules by activating different populations of paracellular pores. J Cell Sci. 2005;118:5221-30.

[37] Van Itallie CM, Holmes J, Bridges A, Gookin JL, Coccaro MR, Proctor W, Colegio OR, Anderson JM. The density of small tight junction pores varies among 
cell types and is increased by expression of claudin-2. J Cell Sci. 2008;121:298-305. [38] Yu AS, Cheng MH, Angelow S, Günzel D, Kanzawa SA, Schneeberger EE, Fromm M, Coalson RD. Molecular basis for cation selectivity in claudin-2-based paracellular pores: identification of an electrostatic interaction site. J Gen Physiol. 2009 ;133:111-27.

[39] Jiang Y, Lee A, Chen J, Ruta V, Cadene M, Chait BT, MacKinnon R. X-ray structure of a voltage-dependent K+ channel. Nature. 2003;423:33-41.

[40] Suzuki H, Nishizawa T, Tani K, Yamazaki Y, Tamura A, Ishitani R, Dohmae N, Tsukita S, Nureki O, Fujiyoshi Y. Crystal structure of a claudin provides insight into the architecture of tight junctions. Science. 2014;344:304-7.

[41] Tsukita S, Katsuno T, Yamazaki Y, Umeda K, Tamura A, Tsukita S. Roles of ZO-1 and ZO-2 in establishment of the belt-like adherens and tight junctions with paracellular permselective barrier function. Ann.NY Acad.Sci. 2009;1165:44-52.

[42] Furuse M, Hata M, Furuse K, Yoshida Y, Haratake A, Sugitani Y, Noda T, Kubo A, Tsukita S. Claudin-based tight junctions are crucial for the mammalian epidermal barrier: a lesson from claudin-1-deficient mice. J Cell Biol. 2002;156:1099-111.

[43] Sugawara T, Iwamoto N, Akashi M, Kojima T, Hisatsune J, Sugai M, Furuse M. Tight junction dysfunction in the stratum granulosum leads to aberrant stratum corneum barrier function in claudin-1-deficient mice. J Dermatol Sci. 2013;70:12-8.

[44] Hou J, Renigunta A, Yang J, Waldegger S. Claudin-4 forms paracellular chloride channel in the kidney and requires claudin-8 for tight junction localization. Proc Natl Acad Sci U S A. 2010;107:18010-5. doi: 10.1073/pnas.1009399107.

[45] Fujita H, Hamazaki Y, Noda Y, Oshima M, Minato N. Claudin-4 deficiency results in urothelial hyperplasia and lethal hydronephrosis. PLoS One. 2012;7:e52272.

[46] Kawai Y, Hamazaki Y, Fujita H, Fujita A, Sato T, Furuse M, Fujimoto T, Jetten AM, Agata Y, Minato N. Claudin-4 induction by E-protein activity in later stages of CD4/8 double-positive thymocytes to increase positive selection efficiency. Proc Natl Acad Sci U S A. 2011;108:4075-80.

[47] Nagatake T, Fujita H, Minato N, Hamazaki Y. Enteroendocrine cells are specifically marked by cell surface expression of claudin-4 in mouse small intestine. PLoS One. 2014;9:e90638. 
[48] Morita K, Sasaki H, Furuse M, Tsukita S. Endothelial claudin:

claudin-5/TMVCF constitutes tight junction strands in endothelial cells. J Cell Biol. 1999;147:185-94.

[49] Ohtsuki S, Sato S, Yamaguchi H, Kamoi M, Asashima T, Terasaki T.

Exogenous expression of claudin- 5 induces barrier properties in cultured rat brain capillary endothelial cells. J Cell Physiol. 2007;210:81-6.

[50] Nitta T, Hata M, Gotoh S, Seo Y, Sasaki H, Hashimoto N, Furuse M, Tsukita S. Size-selective loosening of the blood-brain barrier in claudin-5-deficient mice. J Cell Biol. 2003;161:653-60.

[51] Ben-Yosef T, Belyantseva IA, Saunders TL, Hughes ED, Kawamoto K, Van Itallie CM, Beyer LA, Halsey K, Gardner DJ, Wilcox ER, Rasmussen J, Anderson JM, Dolan DF, Forge A, Raphael Y, Camper SA, Friedman TB. Claudin 14 knockout mice, a model for autosomal recessive deafness DFNB29, are deaf due to cochlear hair cell degeneration. Hum Mol Genet. 2003;12:2049-61.

[52] Kitajiri S, Miyamoto T, Mineharu A, Sonoda N, Furuse K, Hata M, Sasaki H, Mori Y, Kubota T, Ito J, Furuse M, Tsukita S. Compartmentalization established by claudin-11-based tight junctions in stria vascularis is required for hearing through generation of endocochlear potential. J Cell Sci. 2004;117:5087-96.

[53] Niimi T, Nagashima K, Ward JM, Minoo P, Zimonjic DB, Popescu NC, Kimura S. claudin-18, a novel downstream target gene for the T/EBP/NKX2.1 homeodomain transcription factor, encodes lung- and stomach-specific isoforms through alternative splicing. Mol Cell Biol. 2001;21:7380-90.

[54] Li G, Flodby P, Luo J, Kage H, Sipos A, Gao D, Ji Y, Beard LL, Marconett CN, DeMaio L, Kim YH, Kim KJ, Laird-Offringa IA, Minoo P, Liebler JM, Zhou B, Crandall ED, Borok Z. Knockout mice reveal key roles for claudin 18 in alveolar barrier properties and fluid homeostasis. Am J Respir Cell Mol Biol. 2014;51:210-22.

[55] Amasheh S, Meiri N, Gitter AH, Schöneberg T, Mankertz J, Schulzke JD, Fromm M. Claudin-2 expression induces cation-selective channels in tight junctions of epithelial cells. J Cell Sci. 2002;115:4969-76.

[56] Tamura A, Hayashi H, Imasato M, Yamazaki Y, Hagiwara A, Wada M, Noda T, Watanabe M, Suzuki Y, Tsukita S. Loss of claudin-15, but not claudin-2, causes $\mathrm{Na}+$ deficiency and glucose malabsorption in mouse small intestine. 
Gastroenterology. 2011;140:913-23.

[57] Rahner C, Mitic LL, Anderson JM. Heterogeneity in expression and subcellular localization of claudins $2,3,4$, and 5 in the rat liver, pancreas, and gut. Gastroenterology. 2001;120:411-22.

[58] Fujita H, Chiba H, Yokozaki H, Sakai N, Sugimoto K, Wada T, Kojima T, Yamashita T, Sawada N. Differential expression and subcellular localization of claudin-7, -8, -12, -13, and -15 along the mouse intestine. J Histochem Cytochem. 2006;54:933-44.

[59] Tamura A, Kitano Y, Hata M, Katsuno T, Moriwaki K, Sasaki H, Hayashi H, Suzuki Y, Noda T, Furuse M, Tsukita S, Tsukita S. Megaintestine in claudin-15-deficient mice. Gastroenterology. 2008;134:523-34.

[60] Wada M, Tamura A, Takahashi N, Tsukita S. Loss of claudins 2 and 15 from mice causes defects in paracellular $\mathrm{Na}+$ flow and nutrient transport in gut and leads to death from malnutrition. Gastroenterology. 2013;144:369-80.

[61] Alexandre MD, Lu Q, Chen YH. Overexpression of claudin-7 decreases the paracellular $\mathrm{Cl}^{-}$conductance and increases the paracellular $\mathrm{Na}+$ conductance in LLC-PK1 cells. J Cell Sci. 2005;118:2683-93.

[62] Tatum R, Zhang Y, Salleng K, Lu Z, Lin JJ, Lu Q, Jeansonne BG, Ding L, Chen YH. Renal salt wasting and chronic dehydration in claudin-7-deficient mice. Am J Physiol Renal Physiol. 2010 Jan;298:F24-34.

[63] Ding L, Lu Z, Foreman O, Tatum R, Lu Q, Renegar R, Cao J, Chen YH. Inflammation and disruption of the mucosal architecture in claudin-7-deficient mice. Gastroenterology. 2012;142:305-15.

[64] Günzel D, Stuiver M, Kausalya PJ, Haisch L, Krug SM, Rosenthal R, Meij IC, Hunziker W, Fromm M, Müller D. Claudin-10 exists in six alternatively spliced isoforms that exhibit distinct localization and function. $J$ Cell Sci. 2009;122:1507-17.

[65] Breiderhoff T, Himmerkus N, Stuiver M, Mutig K, Will C, Meij IC, Bachmann S, Bleich M, Willnow TE, Müller D. Deletion of claudin-10 (Cldn10) in the thick ascending limb impairs paracellular sodium permeability and leads to hypermagnesemia and nephrocalcinosis. Proc Natl Acad Sci U S A. 2012;109:14241-6.

[66] Hou J, Renigunta A, Konrad M, Gomes AS, Schneeberger EE, Paul DL, 
Waldegger S, Goodenough DA. Claudin-16 and claudin-19 interact and form a cation-selective tight junction complex. J Clin Invest. 2008;118:619-28.

[67] Will C, Breiderhoff T, Thumfart J, Stuiver M, Kopplin K, Sommer K, Günzel D, Querfeld U, Meij IC, Shan Q, Bleich M, Willnow TE, Müller D. Targeted deletion of murine Cldn16 identifies extra- and intrarenal compensatory mechanisms of $\mathrm{Ca} 2+$ and Mg2+ wasting. Am J Physiol Renal Physiol. 2010;298:F1152-61. 


\section{Figure Legends}

Fig. 1.

Epithelial tight junctions (TJs), which are composed of TJ claudin.

A. Location of TJs between epithelial cells.

B. Schematic drawing of a TJ membrane. The plasma membranes of two neighboring cells are closely attached to each other by adhesion molecules (claudins) at the TJs (arrows).

C. Thin section electron micrograph of TJs. The close adherence of two plasma membranes at TJs (arrows) is clearly seen. Bar, $50 \mathrm{~nm}$.

D. Freeze-fracture electron micrograph of a TJ. The freeze-fractured plane of the plasma membrane of a small intestinal epithelial cell is shown. The TJ transmembrane proteins (claudins) form TJ strands. Bar, $50 \mathrm{~nm}$.

E. Crystal structure of claudin-15. The crystal structure of claudin-15 was determined at 2.4 - $\AA$ resolution. It revealed a characteristic $\beta$-sheet fold consisting of five $\beta$-sheets connected to four $\alpha$-helical transmembrane motifs. Please see ref.[40]. C: Cytoplasmic space, E: Extracellular space.

F. Schematic drawing of the molecular structures of claudin-15.

Fig. 2. Variations in the expression patterns of 27 members of the claudin family, according to organ type. The vertical axes indicate the ratio of the claudin mRNA level to that of GAPDH.

Fig. 3. Functions of claudin-based paracellular barriers, revealed by analyses of $\mathrm{KO}$ mice.

A. In the skin, claudin-1 is expressed in the second of three granular cell layers. In claudin-1 KO mice, water inside the body leaks through the skin, and the mice die of dehydration after birth.

B. In claudin-5 KO mice, the blood-brain-barrier, which consists of claudin-5-expressing capillary vessels, is disrupted to allow size-selective solute permeation. The mice die within 10 hours after birth.

C. In stomach-type claudin-18 KO mice, the secreted protons from parietal cells infiltrate the sub-mucosal space, and induce pseudo-pyloric gastritis. 
Fig. 4. Functions of claudin-based paracellular channels, revealed by analyses of $\mathrm{KO}$ mice.

A. In the proximal tubules of the kidney in claudin-2 $\mathrm{KO}$ mice, $\mathrm{Na}+$ reabsorption is disturbed and urinary $\mathrm{Na}+$ is wasted, leading to hypernatriuria.

B. In claudin-2/15 double $\mathrm{KO}$ mice, the paracellular $\mathrm{Na}+$ channel function in the small intestine is severely decreased. As a result, the supply of $\mathrm{Na}+$ from the sub-mucosal space to the intestinal lumen is inhibited, and [Na+] in the intestinal lumen is decreased. The function of $\mathrm{Na}$-dependent nutritional transporters of glucose, amino acids, and bile acids that play roles in lipid absorption, is decreased, leading to lethal malabsorption. 

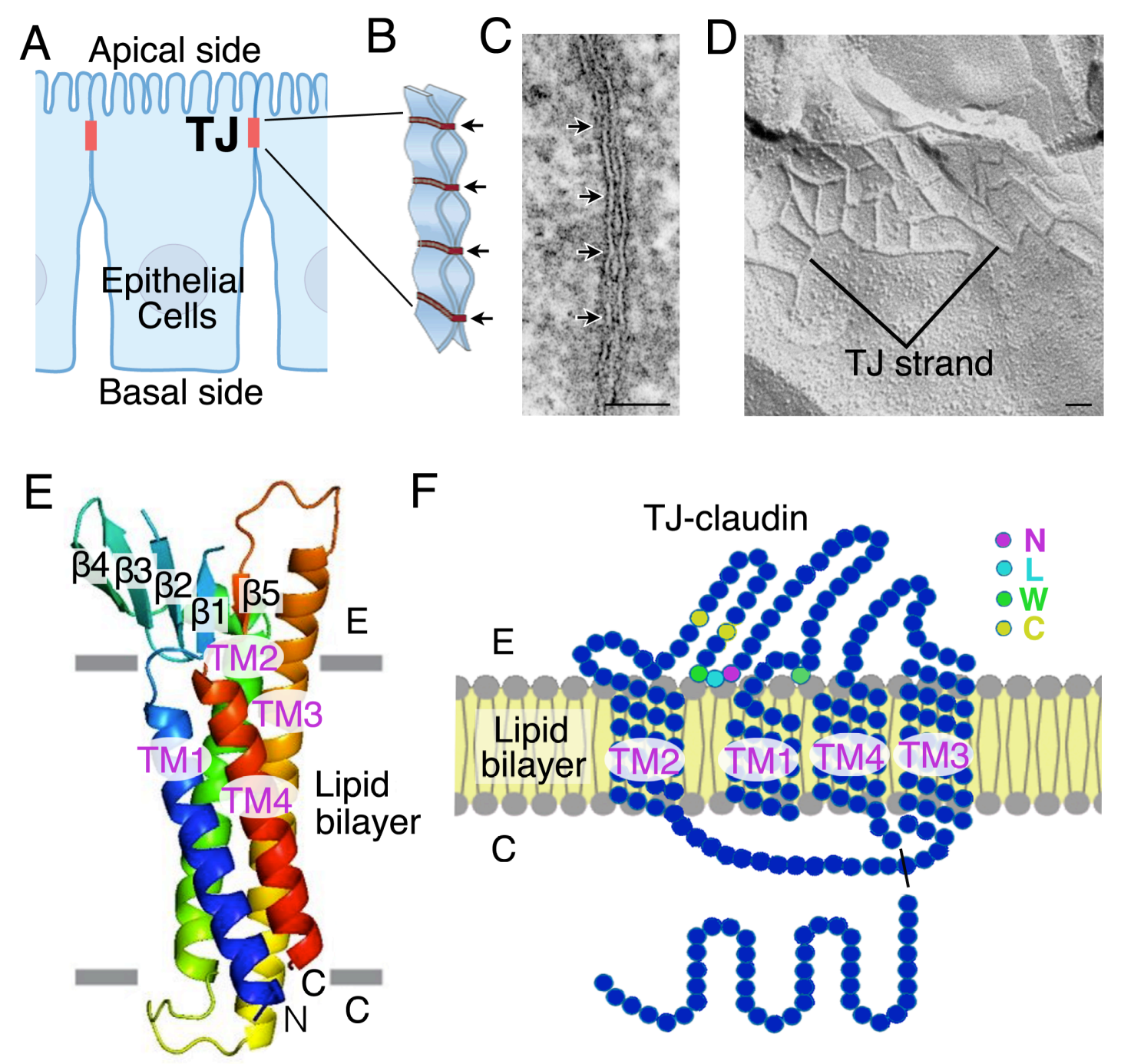

Figure 1 Tamura \& Tsukita 

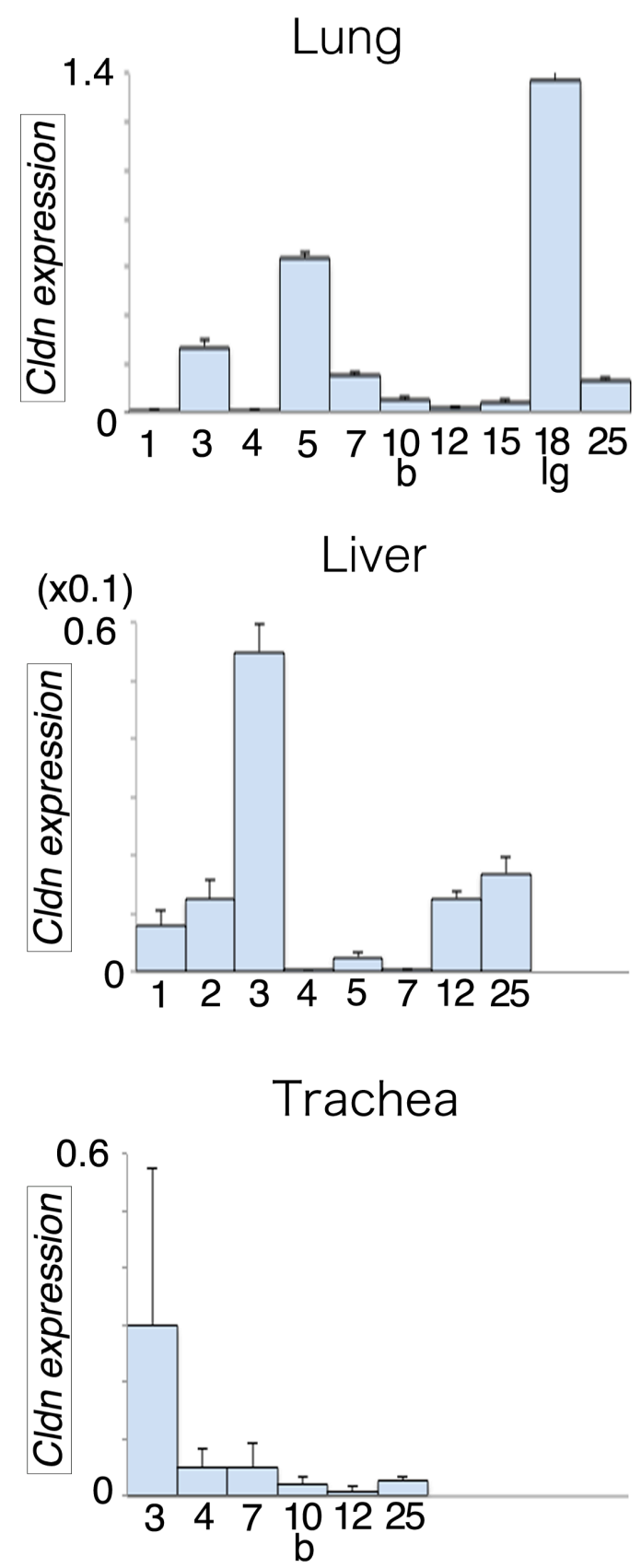

Species of claudins

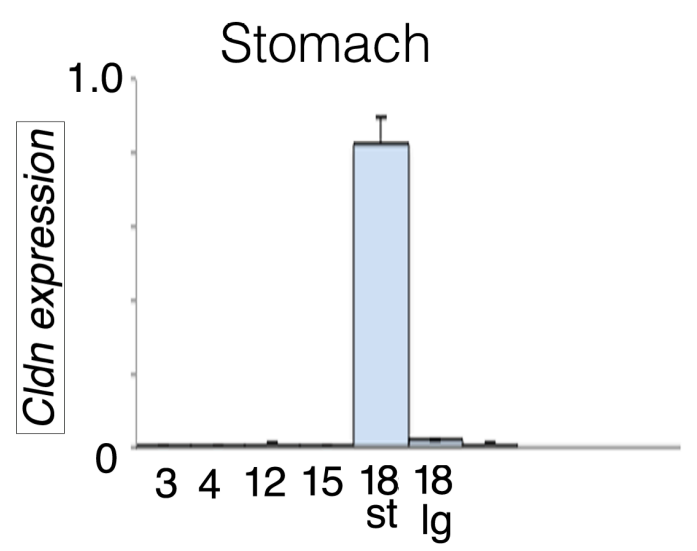

Small intestine

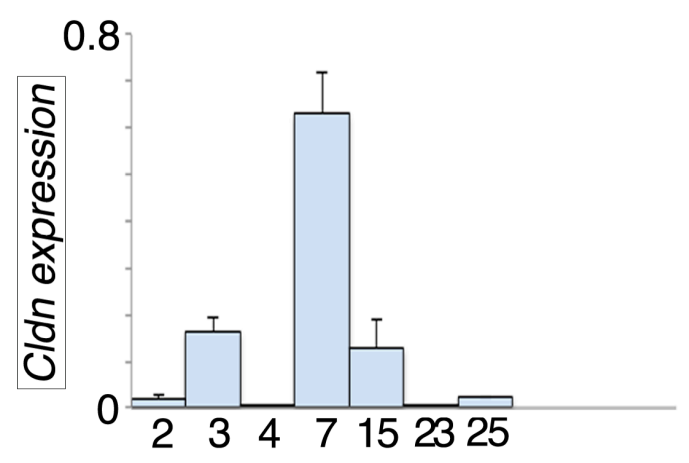

Colon

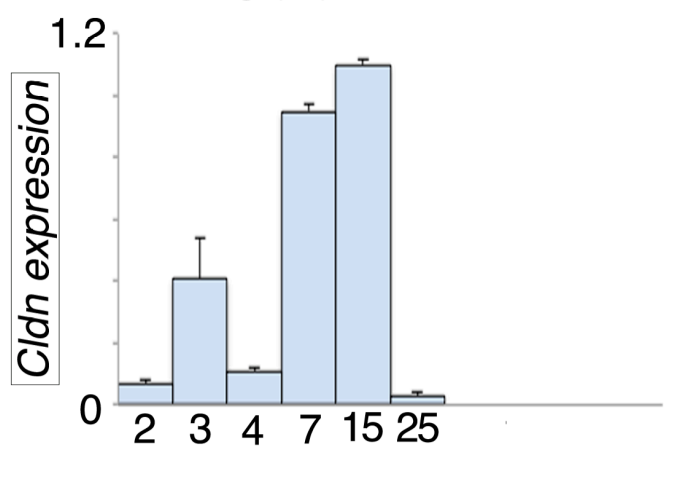

Speices of claudins

Figure 2 Tamura \& Tsukita 

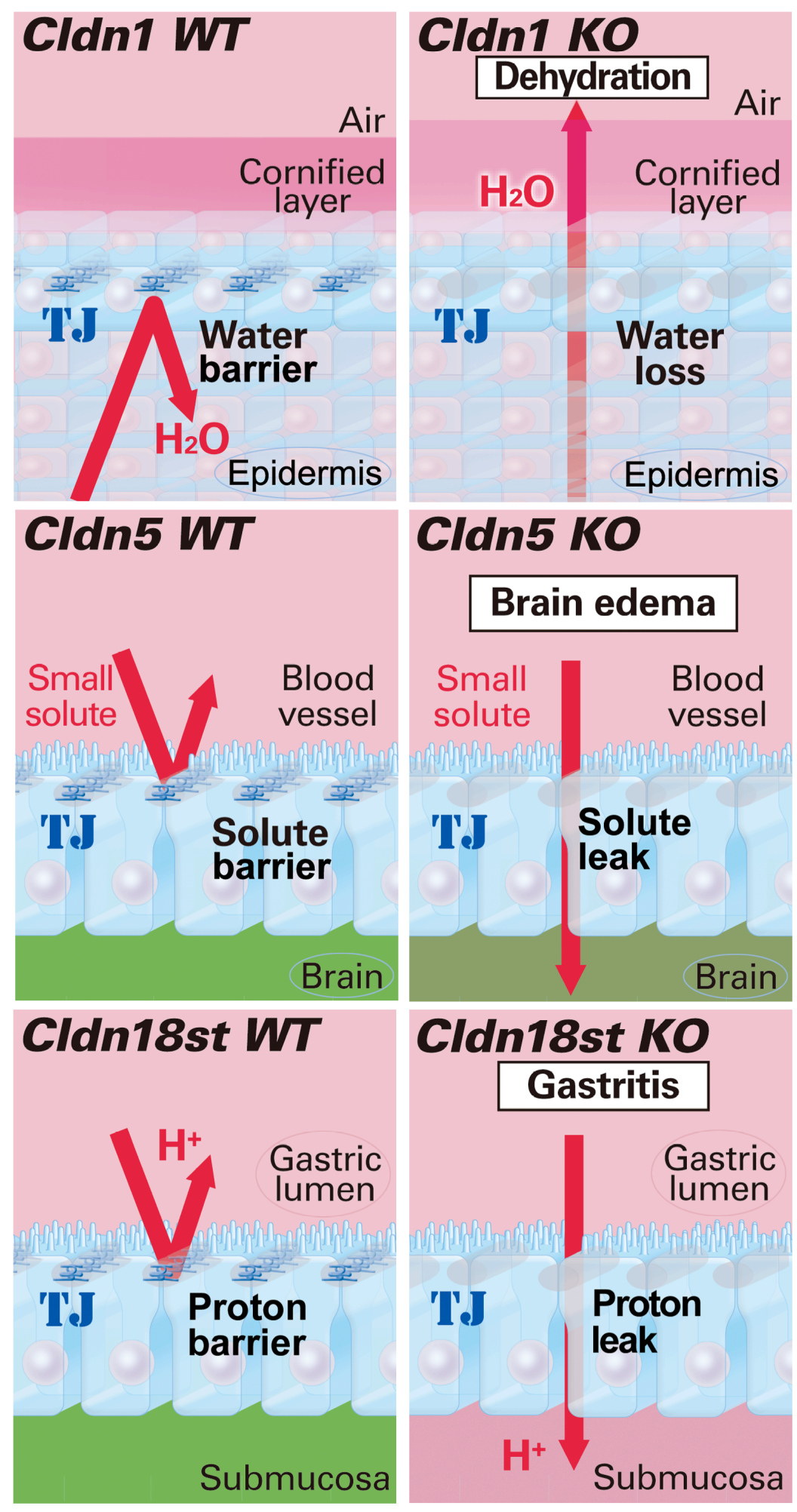

CIdn5 KO

Brain edema
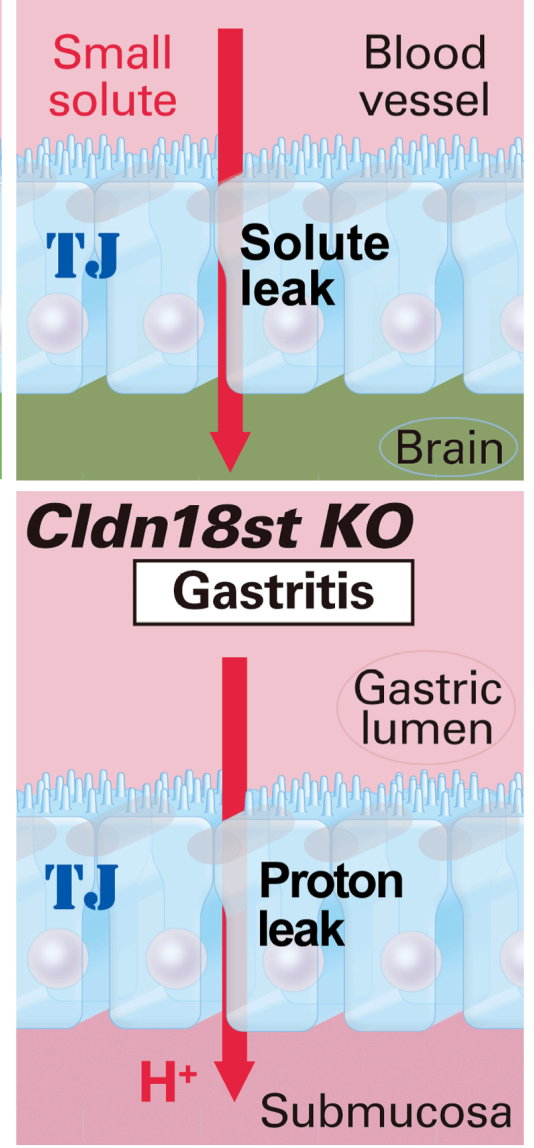

Figure 3 Tamura \& Tsukita 


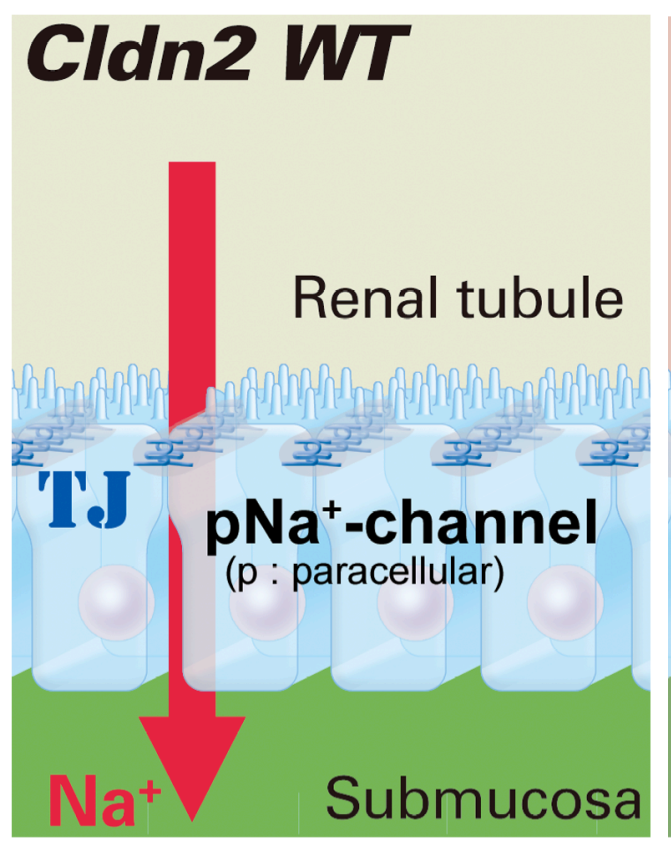

\section{Cldn2 KO}
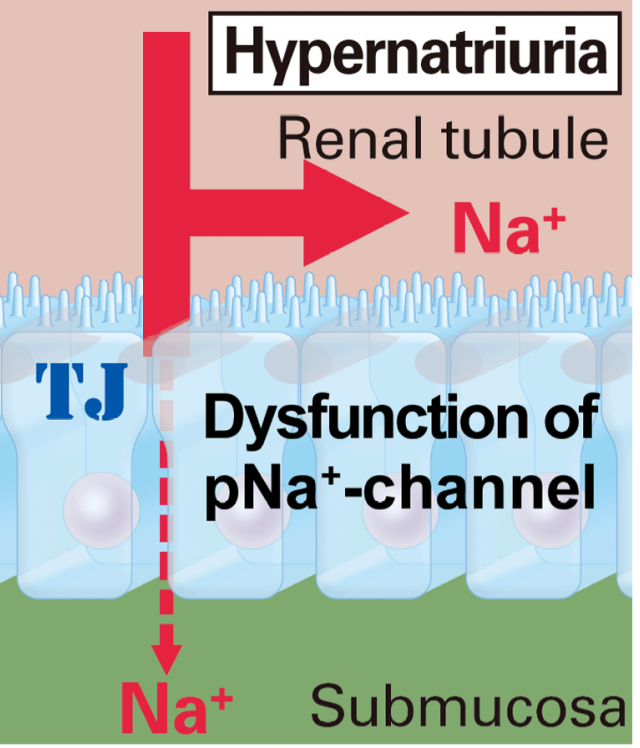

\section{CIdn2/15 WT}

Nutritions

Intestinal lumen
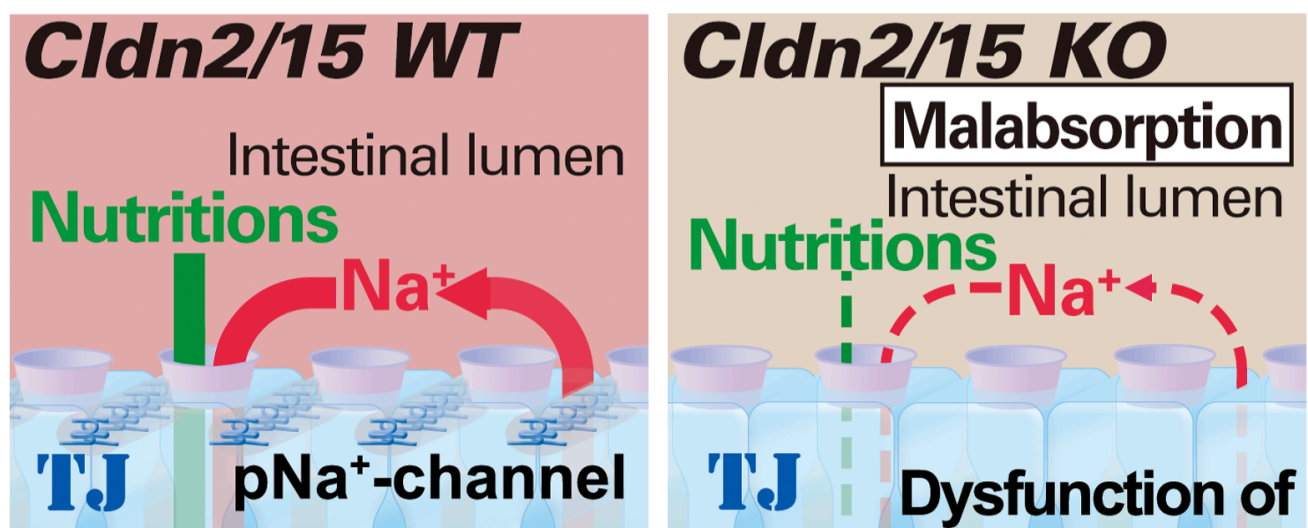

Nutritions

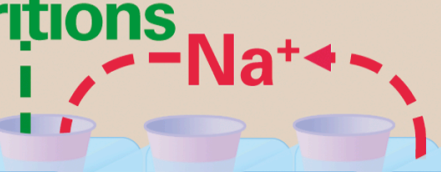

IJ.J Dysfunction of $\mathrm{pNa}^{+}$-channel
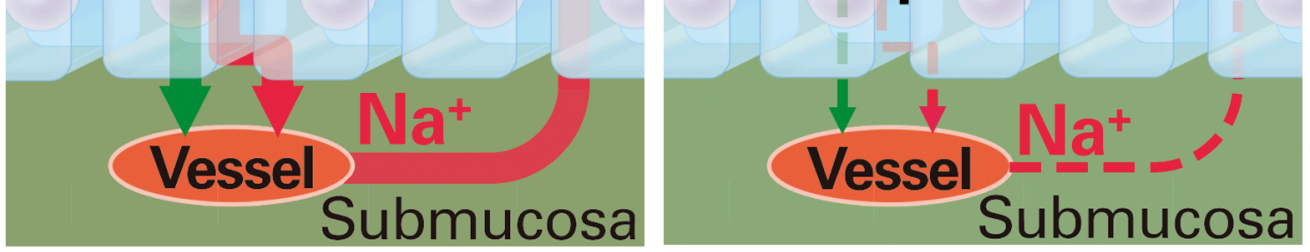

Figure 4 Tamura \& Tsukita 